\title{
Filosofia brasileira como busca por identidade cultural na obra de Henrique de Lima Vaz
}

\section{Brazilian philosophy as search for cultural identity in the work of Henrique de Lima Vaz}

\begin{abstract}
Jair Inácio Tauchen ${ }^{1}$
Pedro Brosina A Musella ${ }^{2}$

\section{Resumo}

Henrique de Lima Vaz foi um dos pensadores brasileiros responsável por diversas conquistas no contexto de expansão da educação no país. Sua análise interpretativa da filosofia decorre do diagnóstico social, cultural e histórico não apenas do Brasil, mas de toda filosofia ocidental. O objetivo do texto é analisar o conceito de identidade cultural brasileira, através dos textos de Lima Vaz, buscando elementos na história da filosofia brasileira as raízes do pensamento no Brasil contemporâneo. O problema consiste em identificar subsídios no contexto histórico e social, que fazem com que a filosofia brasileira seja diferente das demais filosofias ocidentais e como ela se relaciona e se desenvolve na busca por uma identidade cultural brasileira. É possível deduzir que processo de identidade cultural brasileira ainda sofre influência externa e se encontra em formação.
\end{abstract}

\section{Abstract}

Henrique de Lima Vazis one of the Brazilian thinkers responsible for many conquests in the context of the expansion of education in the country. His interpretative analysis of philosophy comes from the social diagnostic, cultural and historic not only from Brazil, but from all of western philosophy. This article's objective is to analyze the concept of Brazilian cultural identity, through Lima Vaz's texts, searching for elements in Brazilian philosophy that create the roots of thought in contemporary Brazil. The problem consists in identifying the substrate in a historical and social context which makes Brazilian philosophy to be so different from the other western philosophies and how it relates and develops as the search for a Brazilian cultural identity. It's possible to deduce that the process of Brazilian cultural identity still suffers of external influence and remains in development.

${ }^{1}$ Pós-doutorando em Filosofia - PUCRS, bolsista PNPD/CAPES. E-mail: jairtauchen@gmail.com
${ }^{2}$ Graduando em Filosofia PUCRS - bolsista BPA/CAPES. E-mail: pedro.musella@acad.pucrs.br 


\section{Introdução}

O contexto da Filosofia no Brasil tem sido palco para os mais variados estudos na atualidade, por diversas razões, algo como um enigma para muitos dos pensadores brasileiros. O fato é que diferentemente da maior parte dos países do mundo, a Filosofia no Brasil chegou atrasada e se desenvolveu de forma inteiramente diferente das demais. Geralmente se tratava de algo puramente artificial, com coletâneas de pensamentos importados de outros países como a França e a Alemanha, que eram reproduzidos por filósofos brasileiros, muitos deles compostos pela elite portuguesa. Nesse contexto histórico tão conturbado, complexo e sutil,torna-se difícil definir o que é a filosofia brasileira e o que pode ser considerado parte dela.

Muitos autores se dedicaram a trabalhar essas questões, todavia seria tarefa impossível em apenas um artigo dar a merecida atenção a cada um deles. Por isso, o estudo terá por objetivo a análise da obra filosófica de Henrique de Lima Vaz3, sobretudo a questão da identidade cultural. O problema consiste em identificar fatores que tornam o Brasil um país diferente na construção da identidade cultural. Para responder esse enigma será feita a comparação de alguns elementos entre as origens da filosofia ocidental com a história da filosofia no Brasil, a fim de encontrar elementos que expliquem esse caráter único e complexo.

\section{A filosofia no contexto social e cultural}

A presença da Filosofia no contexto social e cultural da comunidade humana pode ser vista como algo simples e parte da evolução natural do pensamento humano. Porém, se trata de algo mais complexo, um fenômeno que tem início na criação do pensamento filosófico e se desenvolve em inúmeras ramificações.

\footnotetext{
3 Henrique de Lima Vaz nasceu em 24 de agosto de 1921 em Ouro Preto, Minas Gerais. Foi padre jesuíta e dedicou muitos anos de sua vida ao estudo da Filosofia, tornando-se uma das figuras mais relevantes e mais bem reconhecidas da filosofia brasileira. Foi autor de diversificada coletânea de textos filosóficos, abordando temas que incluía desde metafísica até a ética, dando especial foco a esta última, que foi assunto preponderante na maior parte de sua obra. Desse modo, foi responsável pela divulgação e expansão do pensamento filosófico brasileiro.
} 
Considerando o conceito da filosofia no contexto brasileiro será necessário antes, compreender o que é efetivamente o pensamento que pode ser considerado "filosófico" e como ele originalmente surge no mundo antigo.Essa também era a preocupação demonstrada por Lima Vaz. Considerava que o problema da filosofia no Brasil somente poderia ser formulado a partir de uma origem histórica e cultural sob a ótica da filosofia ocidental como um todo.

Antes, porém, é preciso entender a filosofia e seus efeitos na sociedade; compreender como é a concepção de mundo para o ser humano antes do seu surgimento. Padre Vaz denomina essas sociedades anterior à criação do pensamento filosófico de "pré-filosóficas".

Nas sociedades que poderíamos designar, desde o ponto de vista no qual agora nos situamos, como pré-filosóficas, o indivíduo encontra na vida imediata a totalidade organizada de todos os planos da existência - do sublime divino ao humilde quotidiano que se correspondem e, de alguma maneira, se interpenetram. Ele está então mergulhado, para usar um termo hegeliano, na vida ética concreta (VAZ, 1984, p.1).

De acordo com essa concepção de Vaz (1984, p. 1), os seres humanos pertencentes às sociedades "primitivas", se encontravam em um estado de "unidade" com o restante do mundo e do universo. Se trata da compreensão de todas as coisas percebidas pela mente humana como sendo partes de uma só entidade, independente de quão antagônicas possam ser.

Essa perspectiva pode ser entendida sob a visão filosófica, como também pelo viés psicológico. Por exemplo, os textos de Carl Gustav Jung, fazem inúmeras vezes referência ao estado mental das civilizações primitivas como sendo constituído por um mundo simbólico onde tudo faz parte de uma mesma realidade, que é por sua vez indivisível. Existem, evidentemente, coisas boas e más neste conjunto. Porém, se apresentam com diferentes enfoques, todos representados na mente como símbolos universais. Segundo Jung:

O fato de toda experiência imediata ser psíquica e de a realidade imediata só poder ser psíquica explicam por que é que o homem primitivo coloca espíritos e influências mágicas no mesmo plano que os eventos físicos. Ele ainda não fez de sua experiência original partes antitéticas. Em seu mundo, espírito e matéria ainda se interpenetram, e seus deuses ainda vagam pela floresta e pelo campo (2014, p. 354). 
4 | Opinião Filosófica, V. 10, n. 2, 2019 - Brasil Filosófico e seus pensadores

Para Jung, este estado primordial do pensamento humano não desaparecepor completo na realidade mental moderna, se torna parte dela até na atualidade, sendo porém relocada para o assim chamado "inconsciente coletivo"(Jung, 2002, p.15) um conjunto de conteúdos mentais universais inconscientes que são utilizados por todos os seres humanos para interpretarem o mundo.

Uma vez definida e compreendida a sociedade "pré-filosófica", surge novo problema:como uma sociedade funcionando dentro desses parametros passa a ser uma sociedade "pós-filosófica"? Ou seja, quais os eventos particulares que levam uma sociedade a migrar de uma forma de interpretar o mundo como unidade para uma forma mais complexa recheada de pluralidades e antíteses? Se trata de uma questão relevante cuja resposta escapa até mesmo ao Padre Vaz, que destaca a diversidade social e cultural de um povo sujeito de um processo inteiramente diferente.

As causas são muitas e manifestam a sua diversidade de acordo com as peculiaridades históricas que assinalam o desenvolvimento de determinada cultura. Diversas também se apresentam historicamente as respostas que as sociedades encontram para o problema da ruptura da sua vida imediata(VAZ, 1984, p. 2).

Independentemente das razões particulares que a tenham criado é muito provável que esta evolução cultural tenha se desenvolvido paralelamente ao surgimento da consciência. A partir do momento em que o ser torna-se consciente de si mesmo, percebe que ele é algo que não é equivalente a todas as outras coisas que existem ao seu redor. Através da criação de uma identidade pessoal o ser passa a entender a si mesmo como parte de um todo, porém não equivalente a este.

Isso se amplia ainda mais a partir do momento em que o ser humano percebe que como ser não é nem sequer equivalente a todas as suas partes 4 , neste processo passa do universo do "coletivo" (espécie animal) para o universo do "particular" (identidade).

\footnotetext{
4 Corpo, espírito e alma são exemplos de separações aplicadas a um mesmo indivíduo na antiguidade clássica, tendo como um de seus mais importantes representantes os próprios Gregos. Platão é um dos pioneiros a explorar essa concepção mais a fundo, em seu Mundo das Ideias.
} 
Nada, no entanto, é tão apto a desafiar nossa autoconsciência e alerta como estando em guerra consigo mesmo. Dificilmente se pode pensar em qualquer outro meio, ou mais eficaz, de despertar a humanidade do irresponsável e inocente meio-sono da mentalidade primitiva e levá-la a um estado de responsabilidade consciente (JUNG, 2014, p. 546).

Tal processo pode ser também encontrado de certa forma nos escritos de Platão (2001, p.315), a metáfora da Caverna se mostra particularmente útil neste contexto. Enquanto o homem existe sem a filosofia, vê um mundo de sombras, que são reflexos da realidade. As sombras são projetadas na parede da caverna como uma unidade não singularizada. Ao sair da caverna e ver a luz do sol pela primeira vez, o ser percebe que na verdade a sua realidade é composta por diversos outros seres que em sua particularidade produzem o conjunto de sombras que ele anteriormente entendia como "a realidade".

Uma vez apresentado à realidade como ela é, no entanto, o ser humano passa por uma profunda crise existencial. Existem tantas individualidades que fica difícil organizar o seu pensamento. Ao ver uma árvore não tem mais certeza se de fato trata-se da mesma que viu antes, ou se é algo totalmente diferente. A confusão é tamanha que é preciso buscar aquilo que tinha antes, o "uno" do qual originalmente fazia parte, e assim sendo acaba não intencionalmente criando a abstração, o uso da razão adquirida no processo de individualização, através da qual cria conceitos que são universais e que buscam catalogar a diversidade da realidade em grupos universais. Assim sendo, ao vislumbrar uma árvore o homem não vê aquela árvore em particular. Todavia, consegue admitir que se trata de uma árvore e não de um arbusto. É criada, portanto, a "ideia" de "árvore" como ser universal que tem tais e tais características (ter raízes, ter folhas, ter galhos e etc.). Isso marca a passagem da familiaridade advinda de um dado sensorial para a criação de um conceito5.

\footnotetext{
5 Jung também fala de algo muito próximo em sua obra $O E$ Eu e Inconsciente Coletivo ao comentar sobre a semelhança encontrada entre os delírios de alguns de seus pacientes com conceitos teóricos desenvolvidos por pensadores filosóficos. De acordo com ele os pacientes sofrendo de problemas mentais viviam o conceito como parte da sua realidade e por isso não conseguiam o compreender, enquanto os pensadores que tiveram a mesma percepção conseguiram através da razão abstrair da sua realidade mental conceitos teóricos trazendo assim estes conteúdos para a consciência.
} 
De qualquer maneira, essas respostas se orientam no sentido da reconquista da unidade perdida, sob a forma de um novo sistema de crenças, de uma nova organização social, de uma nova escala de valores. O importante é que, se não todos os indivíduos, ao menos aqueles que alcançam vingar o limiar da nova idade de cultura que se anuncia pela perda da unidade anterior - o fundador de religiões, o gênio político, o reformador moral - tenham a visão clara da nova forma de universalidade que irá estruturar o imaginário social (VAZ, 1984, p. 2-3).

Este processo pode mais uma vez ser extraído do mito da Caverna de Platão. Ao perceber que o novo mundo também se trata de representações, porém desta vez mais complexas, o homem busca pela realidade verdadeira e completa. Antes, a sombra da árvore representava uma falsa imagem da árvore real, era indivisível do restante das sombras, sendo meramente uma "sombra de outro tipo". Uma vez que as árvores reais, como seres particulares no mundo também têm semelhanças entre si, se chega à conclusão de que elas também devem ser representações de um outro tipo, no caso representações da árvore como conceito(ou ideia para Platão), que trata da verdadeira realidade originaria de todo o resto.

A ruptura da vida imediata se caracteriza pela autonomia relativa que os universos simbólicos passam a assumir uns com relação aos outros ou, se assim se pode falar, pela pretensão à universalidade que se eleva dentro da sua própria particularidade (VAZ, 1984, p. $3)$.

Para Vaz, a Filosofia existe como princípio unificador do caos advindo da percepção do mundo como realidade pluralizada, em suas próprias palavras: "...a Filosofia somente surge quando a força unificadora da vida se perdeu ou está ameaçada; a ameaça do caos original volta a pairar sobre o mundo do homem" (VAZ, 1984, p. 4).

De acordo com Lima $\operatorname{Vaz}(1984$, p.15), a filosofia se manifesta em dois eixos principais: o eixo do tempo histórico e o eixo do tempo lógico. O eixo do tempo histórico faz referência ao sujeito que expressa o filosofar, a sua posição no mundo como pertencente a um certo tempo e espaço específicos. Estes se mostram de extrema importância pois são as bases que sustentam a busca pela reintegração, com o "uno" que, por sua vez, tem exigências diferentes dependendo da época e lugar onde se manifesta. 
O tempo histórico é o tempo do sujeito do ato de filosofar e diz respeito à sua situação na sociedade e na cultura de uma época, na qual a necessidade da Filosofia é a necessidade de reinvenção da unidade para o universo de significação que constitui o imaginário social(VAZ, 1984, p.15).

Diferentemente do tempo histórico, o eixo temporal lógico existe como forma através da qual o ato de filosofar se manifesta coerentemente, é o tempo do "objeto do ato se filosofar"(VAZ, 1984, p. 15) em si.E através da junção de ambos os eixos, dentro do contexto da busca pelo retorno ao mundo dos universais é que brota o pensamento filosófico.

Assim,Vaz propõe uma visão de Filosofia como busca por Identidade(1984, p. 2-3-4). O ser humano ao migrar do universo simbólico do homem primitivo para o mundo plural dos conceitos, perde a sua identificação com o restante do universo. Paradoxalmente, ao definir a si mesmo e a sua individualidade, acaba perdendo aquilo que possuía anteriormente, ou seja, a visão de si como parte de um todo maior. Esta cisão se desenvolve de diversas formas na existência humana. O que se ganha em individualidade se perde em significação. $O$ indivíduo se vê como ente único e solitário dentro de um mundo assustador e com o qual ele agora não possui relação direta. Nesse sentido, torna-se oportuno o comentário de Vaz.

A conjunção do tempo histórico e do tempo lógico na gênese e na
estrutura do pensamento filosófico, manifesta-se com exemplar
clareza naqueles domínios da vida e da experiência nos quais
torna-se patente a urgência de se encontrar novas razões para
viver e para agir. Então a Filosofia se justifica como "o próprio
tempo apreendido no conceito": ela não se apresenta como um
jogo intelectual gratuito mas como a necessidade mais profunda
da cultura (VAZ, 1984, p.15).

Disso advém a criação de caminhos para o reencontro da significação dentro do âmbito da individualidade. Por exemplo, da religião, da política e também da Filosofia. Essa última guiada em busca do uno, através do uso do lógos.

\section{A filosofia no contexto da colonização}

Após a compreensão sobre o que pode ser considerado o início da Filosofia como forma de pensar humano e, portanto, comum a todas as suas diversas 
expressões (desde que estas sejam protagonizadas por humanos), é possível agora abordar a próxima questão. O que ocorreu no desenvolvimento da Filosofia no Brasil, que a tornou tão diferente das demais?Esta questão ganha relevância ao se considerar que a Filosofia, como forma de pensamento, é resultado da evolução universal do pensamento humano.

Para se entender propriamente as particularidades da Filosofia Brasileira, antes é preciso entender o que torna o Brasil diferente dos demais locais onde a filosofia deixou sua marca. Ao se analisar o Brasil como país, o primeiro enfoque é a forma como este foi descoberto e construído.Depois disso, é possível perceber que os fatores envolvidos no descobrimento, são responsáveis não só pela formação do pensamento, mas também da estrutura psicológica da cultura brasileira como um todo.

A colonização como forma de expansão cultural foi uma ferramenta utilizada por muitos povos, tantos ocidentais como orientais. Porém, a maneira de efetivação pode variar muito. Lima Vaz, utiliza a expansão grega como exemplo de uma colonização feita de forma a facilitar o nascimento da filosofia. Segundo ele, a interação dos gregos com as culturas próximas foi condição importante para o florescimento da filosofia.

Até o início do período Helenístico em 338 a.C. as Cidades-Estados gregas eram reconhecidas como réplicas em pequena escala da cidade mãe. A colonização tinha como objetivo expandir a cultura grega para outras regiões e criar territórios no qual a cultura da cidade mãe poderia ser vivenciada e ensinada em sua forma mais pura e completa. Segundo Vaz

As colônias gregas primitivas eram réplicas perfeitas da cidademãe e não mantinham com as populações circunvizinhas senão relações de comércio ou, eventualmente, de guerra. Nelas a Filosofia floresceu como em seu terreno nativo(1984, p. 8).

Ao mesmo tempo que mantinham suas cidades e suas culturas intactas, permitiam a propagação de diferentes ideias, o que foi agregado ao legado Helenístico. Atenas ficou conhecida no mundo antigo como a cidade símbolo de cultura, sabedoria, justiça e democracia. Em grande parte, por ser um centro comercial cujas portas estavam abertas para as mais diferentes culturas, o que naturalmente proporcionava uma riqueza em diversidade como nunca antes vista 
na antiguidade. A transferência de cultura dos mais diversos lugares do mundo foi compartilhada, por exemplo, na arte grega. Inclusive, existem comentários de que até mesmo Platão teria estudado em escolas Egípcias.

Mais tarde, em meados de 356 a.C. com o nascimento de Alexandre o Grande, a cultura grega se espalhou por toda a Europa, graças a admiração de Alexandre pela filosofia, sendo ele mesmo um dos alunos de Aristóteles.

A colonização Européia se desenvolveu num processo incrivelmente diferente em muitos níveis. A colônia neste caso,nunca foi idealizada como objetivo de ser extensão de seu país de origem, era vista como território a ser explorado e fonte de recurso.

Processo semelhante ocorreu na colonização do Brasil.Desde o princípio foi idealizado como possibilidade de exploração e lucro para a corte portuguesa e de maneira alguma uma extensão de Portugal. A população local foi explorada para mão-de-obra e sua cultura desprezada pelos colonizadores. Todo esforço consistiu em converter a produção em lucro para a coroa portuguesa.

\section{A filosofia brasileira e a identidade cultural}

Mesmo sob ambiente hostil o período colonial brasileiro se desenvolveu economicamente criando comunidades e dando início a produção cultural. Todavia, uma reprodução do que já existia em Portugal, sem inovação na arte e nem na filosofia.A formação consistia de eruditos portugueses, versados em temas como a Escolástica e produção de textos em latim. No entanto, eram manifestações claramente portuguesas e não tinham nenhuma relação efetiva com a vida colonial brasileira.Para Vaz, isso retira o valor da autenticidade da produção filosófica da época, pois se trata de textos que não representam os interesses sociais e culturais da comunidade nacional. Portanto, fogem de sua concepção de filosofia como busca por uma identidade cultural.

Essas mesmas, teses, provavelmente, eram defendidas na mesma época nos Colégios dos Jesuítas de Viena ou de Praga. Nomes que poderiam figurar numa possível história da Filosofia no Brasil antes da Independência são nomes de personalidade excepcionais para as quais a sociedade colonial não tinha nenhum interesse em si mesma, mas somente enquanto integrada em vastos desígnios 
10 | Opinião Filosófica, V. 10, n. 2, 2019 - Brasil Filosófico e seus pensadores

espirituais ou políticos cujo centro era a metrópole portuguesa e o problema do seu lento declínio econômico, político e cultural(VAZ, 1984, p.10).

Quando o Brasil declarou independência em 1822, pouco mudou do período colonial, exceto a infraestrutura material e a situação política. Embora a literatura tenha enriquecido nesse meio tempo, ainda apresentava traço forte da cultura européia, sobretudo a francesa. A contribuição para a filosofia seguiu o padrão até então estabelecido de somente ecoar aquilo que era preocupação da elite portuguesa.Muito da estrutura social e cultural da época colonialista permaneceu presente tanto no período imperial quanto no período do Brasil república.

Segundo Lima Vaz, somente a partir do Século XX foi possível perceber uma tentativa de desafiar os padrões culturais portugueses e expressar uma voz realmente brasileira.Refere-se mais especificadamente à Semana da Arte Moderna em 1922, que contou com intelectuais como Oswald de Andrade, Mário de Andrade, Heitor Villa-Lobos,Tácito de Almeida entre outros. O renomado compositor brasileiro Villa-Lobos, cuja obra é conhecida no exterior é particularmente um bom exemplo desse movimento, sua participação foi fundamental para a criação de uma identidade cultural brasileira mais definida. Surpreendido com os exóticos ritmos modernos que encontrou em suas viagens para a Europa, Vila-Lobos decidiu buscar uma música originalmente brasileira. Para isso visitou os diferentes Estados do país em busca dos sons locais, e com o que adquiriu construiu a base daquilo que hoje é conhecido como música brasileira, reconhecida mundialmente.

Todavia, é do conhecimento que a Semana da Arte Moderna não foi um sucesso por completo, foi severamente recebida por um público conservador que não tinha interesse algum em deixar a tradição artística portuguesa em nome de algo mais original. No entanto, o fato dela ter ocorrido no contexto histórico da época (independentemente de sua recepção) denota uma mudança no imaginário social e cultural brasileiro, na qual nasce um desejo por uma voz própria que não seja simplesmente um retrato da voz portuguesa. 


\section{Conclusão}

A forma de pensar colonial não abandonou o imaginário social da população brasileira no mundo contemporâneo. Atualmente continua presente em nosso país nos mais variados níveis da sociedade. A relação dual entre colonizador e colonizado se tornou parte da vida brasileira e é encontrada ainda na atualidade,porém de forma diferenciada:é imposta e aceita através do uso de "soft power"6.

A figura do colonizador permanece presente na sociedade brasileira, não mais representado pela coroa portuguesa, mas pela opressão política e econômica revelada por indivíduos e corporações que enxergam o Brasil como uma oportunidade de lucro, uma fonte de riqueza a ser explorada.

O modelo de vida Português no Brasil durante o período colonial não produziu efeitos permanentes somente na literatura, na música, na arte e na cultura Brasileiras, mas também na psyché do povo. Por isso é que o processo de desconexão com o passado colonial e busca por identidade nacional real se apresenta como um problema tão complexo de ser tratado.

Autores como o psiquiatra Italiano Contardo Calligaris, que dedicou parte de seu trabalho na tentativa de melhor compreender o Brasil e a psyché de seu povo,estudou o processo e suas severas ramificações no Brasil contemporâneo.Calligaris comentou surpreso no seu livro Hello Brasil a facilidade com que seus amigos brasileiros falavam negativamente do país, algo que não é comum na Europa.

Deve haver alguma razão que coloca os brasileiros com respeito à própria identidade nacional, em urna curiosa exclusão interna, que permite articular a frase que me interpela. Esta razão não deve datar de hoje [...] Também não se trata - é evidente - de uma falta qualquer de sentimento patriótico. Trata-se de uma dificuldade relativa ao UM, ao qual uma nação refere os seus filhos, relativa ao significante nacional na sua história e na sua significação (CALLIGARIS, 1991, p.14-15).

A urgência do esforço para encontrar a identidade brasileira se torna cada vez mais evidente no mundo contemporâneo. Os fantasmas do colonialismo

${ }^{6}$ Termo de língua Inglesa que faz referência à forma de se manifestar poder passivamente, através do uso da manipulação, propaganda. 
Português ainda assombram a vida psicológica, cultural e social do povo brasileiro que, se manifesta na desigualdade social, no preconceito, na falta de esperança nos políticos responsáveis por introduzir mudanças no país.A espessa camada histórica e cultural de nosso país é responsável pela criação de um complexo de inferioridade atribuída ao "brasileiro" como categoria do próprio ser, e a única forma de o enfrentar reside na filosofia.Não como exercício intelectual que pode ser encontrada no mundo Europeu, mas na filosofia de Henrique de Lima Vaz. Proposta como busca por uma identidade cultural, uma ressignificação do "ser brasileiro" através da redescoberta da unidade do indivíduo com o seu mundo simbólico, cultural e social e a criação de um novo imaginário social do povo brasileiro.

O Brasil é um país rico, com uma beleza natural incomparável, portador de uma imensa quantidade de vida animal e vegetal, assim como, também, uma enorme riqueza mineral. Por conta de sua extensão territorial e populacional o Brasil tem potencial para ser uma nação desenvolvida cultural e socialmente. A mescla de diferentes povos e culturas proporciona um ambiente ideal para $o$ desenvolvimento de ideias e o compartilhamento de experiências vindas de todos os cantos do mundo. Até mesmo a natureza parece dar um especial carinho ao país, sendo um dos poucos lugares na terra onde não existe a frequente ameaça de desastres naturais como ciclones, tsunamis ou terremotos.

Mesmo assim, sabendo de tudo o que tem, o povo brasileiro continua se vendo como trabalhador do terceiro mundo, pobre e miserável. Essa imagem em grande parte é o resultado da desigualdade social imposto pelo sistema colonialista que imperou e impera na sociedade brasileira. É responsabilidade do próprio povo brasileiro transcender esta condição, para que nas futuras gerações possa emergir um novo Brasil, um país que faça uso de toda a riqueza que possui, e que deixe no passado o símbolo de pobreza, desonestidade e desigualdade. Pode ser árduo, difícil, mas não impossível. O desenvolvimento cultural, da tecnologia e dos meios de comunicação podem contribuir para um Brasil sustentável e inclusivo. Trata-se de uma oportunidade sem precedente histórico, através da Filosofia, encontrar uma identidade cultural de conotação positiva e de se desvencilhar da estrutura já ultrapassada do colonialismo Português. 


\section{Referências}

CALLIGARIS, Contardo. Hello Brasil: notas de um Psicanalista Europeu Viajando ao Brasil. 2. ed. São Paulo: Escuta, 1991.

JUNG, Carl Gustav. Modern Man in Search of a Soul. 2. ed. London and New York: Psychology Press, 2001.

JUNG, Carl Gustav. Os Arquétipos e o Inconsciente Coletivo. 2. ed. Petrópolis: Vozes, 2002.

JUNG, Carl Gustav. The Collected Works of C.G. Jung. 1. ed. Nova Jersey: Princeton University Press, 2014.

PLATÃO. A República. 9. ed. Lisboa: Fundação Calouste Gulbenkian, 2001.

VAZ, H. C. D. L. A cultura e seus fins. Síntese, Belo Horizonte, v. 19, n. 57, p. 149159, fev./1992.

VAZ, H. C. D. L. A Filosofia no Brasil, hoje. Cadernos SEAF, Volume, n. 1, 1978.

VAZ, H. C. D. L. O Problema da Filosofia no Brasil. Síntese, Belo Horizonte, v. 1, n. 30, p. 11-25, jan./1984.

Recebido em: 27/12/2019.

Aprovado em: 27/12/2019. 